\title{
Virus et bactéries atypiques détectés dans les infections respiratoires basses communautaires de l'enfant dans la région de Sfax en Tunisie*
}

\author{
Virus and Atypical Pathogens Detected in Community-Acquired Lower Respiratory Tract \\ Infection in Infants and Children of Sfax Region, Tunisia
}

\author{
L. Fki Berrajah $\cdot$ K. Aïssa Ben Slama $\cdot$ I. Khbou $\cdot$ S. Gargouri $\cdot$ A. Chtourou $\cdot$ A. Znazen $\cdot$ M. Kassis $\cdot$ S. Yaich \\ A. Hammami - M. Hachicha - A. Vabret - H. Karray Hakim
}

Reçu le 27 novembre 2017; accepté le 16 avril 2018

(C) Société de pathologie exotique et Lavoisier SAS 2018

Résumé Le profil étiologique microbien des infections respi-
ratoires basses (IRB) communautaires de l'enfant a été peu
étudié en Tunisie. Une étude prospective a été menée à Sfax
entre janvier 2009 et mars 2010 sur 368 enfants hospitalisés
pour pneumonie $(n=78)$ ou bronchiolite aiguë $(n=290)$. Les
aspirations nasopharyngées ont été analysées par immuno-
fluorescence et par PCR à la recherche des virus influenza,
virus para-influenza, virus respiratoire syncytial (VRS), méta-
pneumovirus, rhinovirus, entérovirus, adénovirus, coronavi-
rus, Mycoplasma pneumoniae (Mpn) et Chlamydia pneumo-
niae $(\mathrm{Cpn})$. Une étiologie ou plus a été retrouvée dans 319 cas
$(86,7 \%)$ : principalement le VRS $(42,7 \%)$, des rhinovirus

L. Fki Berrajah · I. Khbou · S. Gargouri · A. Chtourou

A. Znazen · A. Hammami $\cdot$ H. Karray Hakim $(\bowtie)$

Laboratoire de microbiologie, faculté de médecine de Sfax, université de Sfax, Tunisie

e-mail : hela_hakim@yahoo.fr

CHU Habib Bourguiba, rue El-Ferdaous, 3029 Sfax, Tunisie

K. Aïssa Ben Slama · M. Hachicha

Faculté de médecine de Sfax, université de Sfax, Tunisie

K. Aïssa Ben Slama · M. Kassis · S. Yaich · M. Hachicha Service de pédiatrie, CHU Hédi Chaker, route El-Aïn, 3029 Sfax, Tunisie

M. Kassis $\cdot$ S. Yaich

Service médecine communautaire et d'épidémiologie, CHU Hédi Chaker, route El-Aïn, 3029 Sfax, Tunisie ; faculté de médecine de Sfax, université de Sfax, Tunisie

\section{A. Vabret}

Laboratoire de virologie, CHU de Caen,

14000 Caen, France

\footnotetext{
* Source de financement : ce travail a été financé par le CHU Habib-Bourguiba de Sfax dans le cadre d'un projet de recherche intitulé « Identification des étiologies virales et bactériennes des infections respiratoires basses du nourrisson et de l'enfant dans la région de Sfax ».
}

(32,9 \%) et des adénovirus (28,5\%). Dans $40 \%$ des prélèvements positifs, deux ou trois agents pathogènes ont été codétectés. Cette étude a permis de montrer la prévalence élevée des virus dans les IRB de l'enfant dans la région de Sfax et leur détection fréquente en co-infection posant la question sur leur rôle pathogène réel.

Mots clés Infection respiratoire basse $\cdot$ Enfant $\cdot$ Virus respiratoires · Virus influenza · Virus respiratoire syncytial · Virus para-influenza $\cdot$ Bactéries atypiques · Codétection · Co-infection · Hôpital $\cdot$ Sfax $\cdot$ Tunisie $\cdot$ Afrique du Nord

Abstract Little is known about viral and atypical bacteria pathogen spectra of community-acquired lower respiratory tract infection in children in Tunisia. Thus, a prospective study was carried out between January 2009 and March 2010 in Sfax. Nasopharyngeal aspirates collected from 368 patients (78 with pneumonia and 290 with acute bronchiolitis) were analyzed by indirect immunofluorescence assay and PCR to detect influenza viruses, parainfluenza viruses, respiratory syncytial virus (RSV), human metapneumovirus, human rhinovirus, human enterovirus, adenovirus, coronavirus, $\mathrm{Myco-}$ plasma pneumonia (Mpn) and Chlamydia pneumonia (Cpn). One or more etiology was documented in 319 cases (86.7\%). The most detected viruses were RSV (42.7\%), rhinovirus $(32.9 \%)$ and adenovirus $(28.5 \%)$. Co-detection of two or three pathogens was found in $40 \%$ of positive samples. This study highlights the importance of respiratory viruses in lower respiratory tract infection in children of Sfax region as well as the high rate of co-detection of multiple viruses, resulting in challenges in clinical interpretation.

Keywords Lower respiratory infection - Infants and children · Respiratory viruses · Influenza virus · Respiratory syncytial virus · Parainfluenza virus · Atypical bacteria $\cdot$ Co-detection $\cdot$ Co-infection $\cdot$ Hospital $\cdot$ Sfax . Tunisia $\cdot$ Northern Africa 


\section{Introduction}

Les infections respiratoires basses (IRB) de l'enfant regroupent les atteintes infectieuses du parenchyme pulmonaire, des bronches et de la trachée. Elles représentent un problème majeur de santé publique, associées à un taux d'hospitalisation et à une mortalité (létalité) élevée, particulièrement dans les pays en voie de développement [24]. Ces infections touchent le plus souvent l'enfant âgé de moins de cinq ans. Le spectre des pathogènes responsables de cette infection est vaste incluant essentiellement des virus, des bactéries ainsi que des co-infections virus-bactéries. Le diagnostic microbiologique de ces infections a beaucoup progressé grâce à la biologie moléculaire qui a permis d'améliorer la sensibilité de détection des virus et des bactéries atypiques par rapport aux techniques conventionnelles (culture cellulaire et détection d'antigènes viraux).

Le profil des pathogènes retrouvés dépend du type de l'infection respiratoire, de l'âge de l'enfant et des données épidémiologiques du pays. En Tunisie, l'incidence des IRB chez les enfants de moins de cinq ans est de 99800 cas par an, et plus de 200 enfants en décèdent chaque année [24]. Dans la région de Sfax, ces infections représentent 15 à $20 \%$ de l'activité hospitalière du service de pédiatrie du centre hospitalo-universitaire (CHU) Hédi-Chaker de Sfax. Malgré la place occupée par cette pathologie, son profil étiologique microbien n'a pas été suffisamment exploré ni dans notre région ni en Tunisie, d'où l'objectif de cette étude.

\section{Patients et méthodes}

C'est une étude prospective menée par le laboratoire de microbiologie du CHU Habib-Bourguiba de Sfax en collaboration avec le service de pédiatrie générale du CHU HédiChaker de Sfax. Cette étude a été réalisée dans le cadre d'un projet de recherche intitulé "Identification des étiologies virales et bactériennes des infections respiratoires basses du nourrisson et de l'enfant dans la région de Sfax » financé par notre hôpital.

Nous avons inclus 368 enfants âgés de 1 mois à 15 ans, hospitalisés dans le service de pédiatrie entre janvier 2009 et mars 2010 pour une symptomatologie respiratoire aiguë en rapport avec une IRB. Le diagnostic de la bronchiolite aiguë a été porté devant l'apparition, après une rhinopharyngite peu ou pas fébrile, d'une toux, dyspnée obstructive avec polypnée, freinage, signes de lutte, distension thoracique (clinique et/ou radiologique), wheezing, râles sibilants et/ou râles crépitants et sous-crépitants diffus à prédominance expiratoire. Le diagnostic de la bronchite a été porté devant une toux productive, modérément fébrile, survenant au décours d'une rhinopharyngite, associée à des râles ronflants à l'auscultation pulmonaire. La pneumonie aiguë commu- nautaire a été retenue devant l'association de signes cliniques (toux, tachypnée, fièvre survenant en ambulatoire ou avant 48 heures d'hospitalisation et râles crépitants à l'auscultation pulmonaire) et radiologiques (opacités parenchymateuses). N'ont pas été inclus les enfants présentant une maladie respiratoire chronique y compris l'asthme, une maladie neuromusculaire, une cardiopathie congénitale ou un déficit immunitaire.

Un consentement éclairé des parents a été obtenu pour la réalisation de l'enquête microbiologique et pour le suivi. L'éthique a été respectée, étant donné que la prise en charge des patients rentrait dans le cadre habituel du diagnostic et du traitement de telles pathologies. De plus, les parents n'ont manifesté aucune objection à l'exploitation des données des dossiers cliniques de leurs enfants.

Des prélèvements d'aspiration nasopharyngée (ANP) ont été effectués lors des séances de kinésithérapie respiratoire chez tous les patients inclus, puis acheminés rapidement au laboratoire. Contrairement aux pays anglo-saxons, la kinésithérapie respiratoire dans les bronchiolites aiguës du nourrisson est largement prescrite dans les pays européens francophones et en Tunisie où on privilégie les techniques expiratoires passives et lentes, associées à la toux provoquée (technique d'augmentation du flux expiratoire). La Société tunisienne de pédiatrie recommande depuis 2013 la kinésithérapie respiratoire au cas par cas, en cas d'encombrement bronchique important ou atélectasie. Comme notre étude est antérieure à ces recommandations, la kinésithérapie respiratoire a été réalisée chez tous les patients.

Les prélèvements ont été analysés prospectivement par immunofluorescence indirecte (IFI). Des aliquotes à partir de chaque échantillon ont été conservées à $-80{ }^{\circ} \mathrm{C}$ pour effectuer ultérieurement le diagnostic moléculaire.

\section{Recherche des antigènes viraux par IFI}

Elle a été effectuée en utilisant des anticorps monoclonaux spécifiques (ARGENE, France) et des anti-immunoglobulines de souris conjuguées à la fluorescéine (DAKO, Danemark). Les virus recherchés étaient : les virus influenza (VI) A et B (VIA et VIB), virus respiratoire syncytial (VRS) et virus parainfluenza (VPI) 1, 2 et 3 (VPI1, VPI2 et VPI3).

\section{Diagnostic moléculaire}

Il a été utilisé pour la recherche de 16 virus et deux bactéries atypiques. Les ARN et ADN ont été extraits simultanément à partir de $200 \mu \mathrm{l}$ de sécrétions nasopharyngées à l'aide de la trousse QIAamp MinElute Virus Spin (QIAgen, Hilden Germany). Quatre RT-PCR Multiplex (PCRm) et deux réactions de PCR en temps réel ont été ensuite réalisées. Les deux premières RT-PCRm simples ont été utilisées pour la détection du VIC, rhinovirus humain $(\mathrm{RhV})$ et entérovirus humain 
$(\mathrm{EntV})$ pour l'une et les coronavirus (CoV) OC43, 229E, NL63 et HKU1 pour l'autre. Les deux autres RT-PCRm étaient semi-nichées permettant l'une la détection des VIA, VIB, VRS A-B, métapneumovirus humain (MPVh) et l'autre celle des VPI1 à 4, sachant que le second tour de PCR n'a été pratiqué que pour les échantillons négatifs après le premier tour. Toutes ces réactions ont été effectuées selon des procédures déjà décrites $[1,28,29]$. La révélation des produits de PCR éventuellement formés a été réalisée par une électrophorèse sur gel d'agarose à $2 \%$. Les deux réactions de PCR en temps réel utilisées étaient l'une monoplex détectant les adénovirus ( $\mathrm{AdV}$ ) et l'autre multiplex détectant Chlamydia pneumoniae (Cpn) et Mycoplasma pneumoniae $(\mathrm{Mpn})$. Ces deux réactions, déjà décrites $[8,13,30]$, sont fondées sur la technologie des sondes d'hydrolyse (Taqman Assay). L'amplification a été réalisée sur le thermocycleur CFX96 ${ }^{\text {TM }}$ Real-Time System (Bio-RAD).

Pour la recherche virologique, la première centaine d'échantillons a été explorée dans le laboratoire de virologie du CHU Clémenceau de Caen, France. Le reste des prélèvements a été analysé dans notre laboratoire en utilisant les mêmes techniques et réactifs.

\section{Étude statistique}

Les données ont été analysées avec différents outils statistiques en utilisant le logiciel SPSS version 20. La comparaison de deux moyennes (variables quantitatives) sur séries indépendantes a été effectuée au moyen du test de Student. La comparaison des pourcentages (variables qualitatives) a été effectuée par le test de $\mathrm{Chi}^{2}$ de Pearson en utilisant des tables de contingence. Les différences étaient considérées significatives si $p$ inférieur à 0,05 .

\section{Résultats}

\section{Caractéristiques des patients}

Durant la période d'étude, parmi les 368 enfants inclus, 290 ont été hospitalisés pour bronchiolite aiguë et 78 pour pneumonie. Aucun cas de bronchite n'a nécessité d'hospitalisation durant la période d'étude. Le sex-ratio était de 1,69 (231 garçons/137 filles). La moyenne d'âge était de 7,03 mois (extrêmes : 1 mois et 7 ans 3 mois). La distribution des patients en fonction de la tranche d'âge et du diagnostic (Fig. 1) montre que 310 enfants (84,2\%) étaient âgés d'un an ou moins dont 251 (81\%) d'âge inférieur ou égal à six mois. Les enfants atteints de pneumonie étaient significativement plus âgés que ceux atteints de bronchiolite avec des moyennes d'âge respectivement de 15,38 et 4,78 mois ( $\mathrm{p}<$ 0,001 ) et des extrêmes d'âge respectivement de 1 et 87 mois et de 1 et 23 mois. Cinq enfants seulement étaient âgés de plus de cinq ans et avaient une pneumonie.

\section{Recherche d'une étiologie virale}

Durant la période d'étude, la majorité soit 268 prélèvements (72,8 \%) ont été reçus au laboratoire durant les deux saisons froides de l'étude, soit de janvier à mars en 2009 et en 2010 (Fig. 2).

En combinant les résultats de l'IFI et de la PCR, au moins un virus a été retrouvé chez 319 (86,7\%) des 368 enfants explorés avec un total de 467 virus détectés. On note la prédominance du VRS (42,7\%), suivi par le RhV (32,9\%) et l'AdV (28,5\%) (Tableau 1). Ces trois virus constituent à eux seuls $82 \%$ des 467 virus détectés. Le VRS était significativement plus retrouvé dans les bronchiolites $(p=0,016)$ alors que

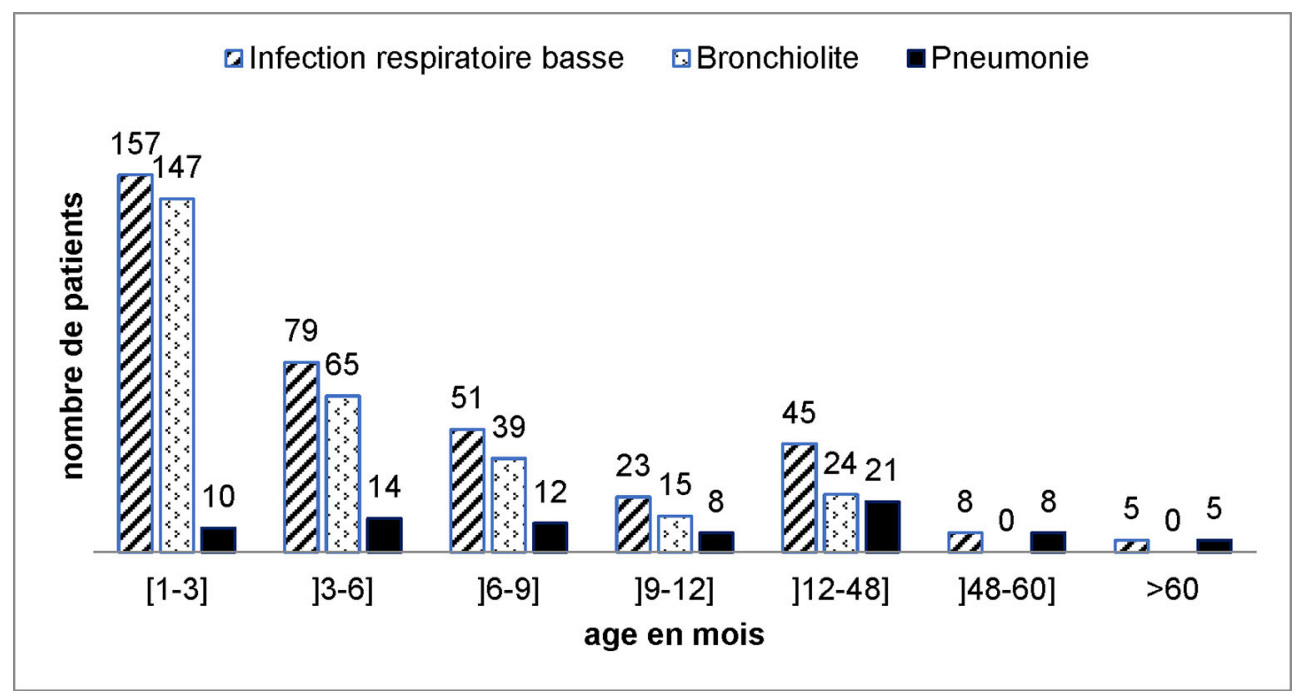

Fig. 1 Distribution des patients étudiés selon l'âge et le type d'atteinte respiratoire / Distribution of enrolled patients according to the age and the type of respiratory infection 


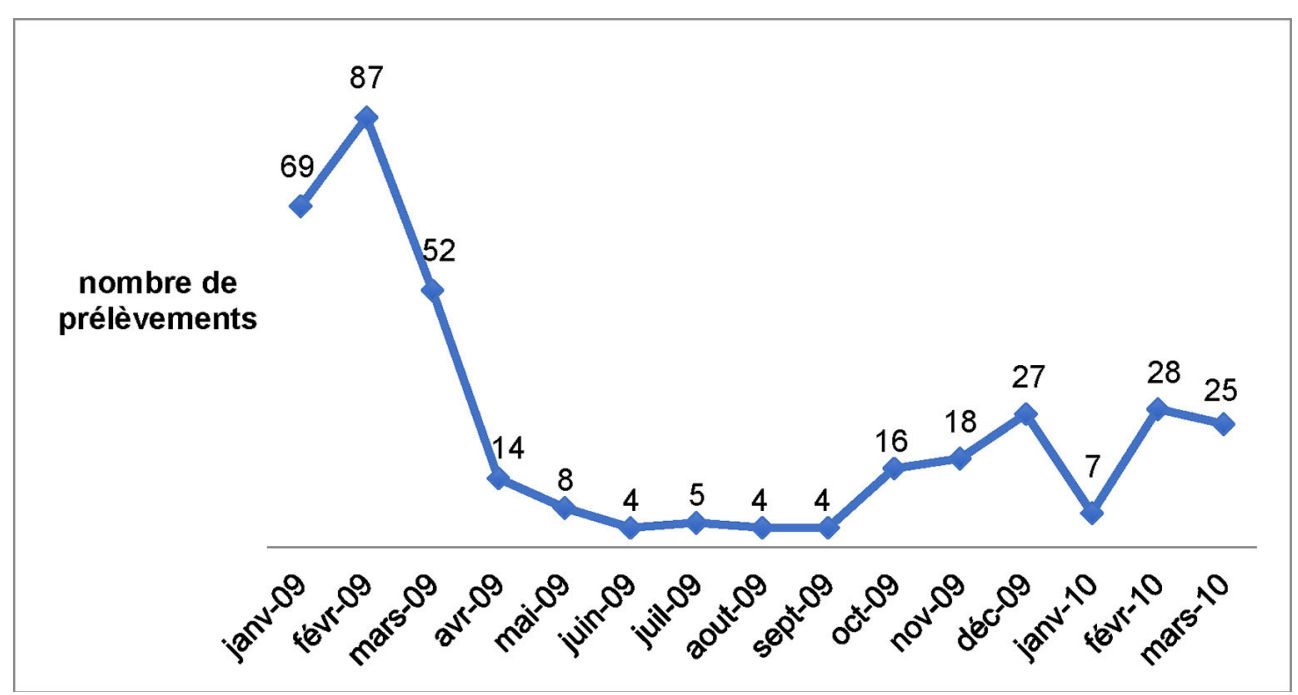

Fig. 2 Nombre d'échantillons d'aspiration nasopharyngée reçus par mois durant la période d'étude / Monthly distribution of nasopharyngeal aspirates collected during the study period

l'AdV était plus fréquemment détecté dans les pneumonies $(p=0,022)$. Les EntV viennent en quatrième position avec 27 cas. Parmi les virus influenza $(n=21)$ et para-influenza $(n=23)$, les plus fréquemment détectés étaient respectivement le VIA ( 15 cas) et le VPI3 (13 cas). Quant aux coronavirus, ils étaient dominés par le CoV-NL63, retrouvé dans cinq cas.

En tenant compte de l'âge des patients, le VRS était significativement plus fréquent chez les enfants âgés de moins de six mois comparés à ceux âgés de plus de six mois, et cela, quel que soit le type d'atteinte, soit 53,8 \% (127/236) versus $22,7 \%(30 / 132)$ (Tableau 2). L'AdV était plus fréquent chez les enfants âgés de plus de six mois ( 55 versus 50 ), et cette différence était statistiquement significative chez les enfants atteints de bronchiolite $(p<0,001)$. De même, le MPVh n'était retrouvé qu'à partir de six mois $(p=0,005)$. Concernant le reste des virus, aucune différence n'a été trouvée.

\section{Recherche des bactéries atypiques}

Les bactéries atypiques ont été détectées chez cinq enfants. Il s'agissait de Mpn dans deux cas ( $0,5 \%)$ et Cpn dans trois cas $(0,8 \%)$. Les deux enfants infectés par Mpn avaient une pneumonie et étaient âgés respectivement de 5 et 14 mois. Parmi les trois enfants infectés par Cpn, deux avaient une bronchiolite et étaient âgés respectivement de 1 et 17 mois. Le troisième avait une pneumonie et était âgé de 60 mois.

\section{Fréquences de détection de chaque pathogène retrouvé seul ou en co-infection}

Globalement, une différence statistiquement significative a été retrouvée uniquement pour les $\mathrm{AdV}, \mathrm{RhV}$, EntV et VPI, plus fréquemment retrouvés en co-infection qu'en mono- infection (Tableau 3). Cette différence a été retrouvée aussi bien dans les pneumonies que dans les bronchiolites pour les deux premiers virus cités. Parmi les 14 cas de co-infection à VPI, dix étaient liés au sérotype 3. Par contre, le MPVh a été retrouvé dans quatre cas sur cinq en mono-infection.

Le profil des co-infections retrouvées dans cette étude (Tableau 4) montre 106 cas de co-infection à deux pathogènes qui étaient liés principalement à l'association $\mathrm{AdV}$ RhV et AdV-VRS (retrouvée chacune dans 29 cas), suivie par l'association RhV-VRS (12 cas). Les 24 cas de coinfection à trois pathogènes étaient représentés essentiellement par l'association AdV-RhV à laquelle s'ajoute le VRS dans sept cas, Cpn dans un cas et divers autres virus chez le reste des patients.

Au total, 193 ANP étaient positives à un seul virus, mais deux d'entre elles étaient également positives à Cpn ou Mpn. Parmi les cinq prélèvements positifs à bactéries atypiques, un contenait un seul pathogène (un cas de pneumonie à Cpn). Ainsi, une étiologie virale et/ou bactérienne a été retrouvée chez 320 patients. Il s'agissait d'une monoinfection virale ou bactérienne dans 192 cas soit $60 \%$ et d'une co-infection virus-virus $(n=124)$ ou virus-bactérie $(n=4)$ dans $40 \%$ des cas.

\section{Répartition mensuelle des virus trouvés}

La majorité des virus (335, soit 71,6\%) a été détectée entre les mois de janvier et mars de 2009 et de 2010 (Tableau 5). La principale étiologie retrouvée durant ces mois en 2009 était le VRS qui a représenté à lui seul 53,6\% des 280 virus détectés durant cette période. Cette prédominance n'a pas été retrouvée durant les mêmes mois de l'année suivante puisque le VRS a été quasiment remplacé par les RhV et 


\begin{tabular}{|c|c|c|c|c|}
\hline Virus & $\begin{array}{l}\text { Bronchiolite }(n=290) \\
\text { Nombre de patients }(\%)^{\mathrm{a}}\end{array}$ & $\begin{array}{l}\text { Pneumonie }(n=78) \\
\text { Nombre de patients }(\%)^{b}\end{array}$ & $p$ & $\begin{array}{l}\text { Total }(n=368) \\
\text { Nombre de patients }(\%)^{\mathrm{c}}\end{array}$ \\
\hline VRS & $135(46,6)$ & $22(28,5)$ & 0,016 & $157(42,7)$ \\
\hline $\mathrm{AdV}$ & $77(26,6)$ & $28(35,9)$ & 0,022 & $105(28,5)$ \\
\hline $\mathrm{RhV}$ & $95(32,8)$ & $26(33,3)$ & 0,46 & $121(32,9)$ \\
\hline EntV & $24(8,3)$ & $3(3,8)$ & 0,25 & $27(7,3)$ \\
\hline VI & $15(5,2)$ & $6(7,7)$ & 0,26 & $21(5,7)$ \\
\hline VIA & $10(3,4)$ & $5(6,4)$ & & $15(4,1)$ \\
\hline VIB & $1(0,3)$ & $1(1,3)$ & & $2(0,5)$ \\
\hline VIC & $4(1,4)$ & 0 & & $4(1,1)$ \\
\hline VPI & $18(6,2)$ & $5(6,4)$ & 0,78 & $23(6,3)$ \\
\hline VPI1 & $5(1,7)$ & $1(1,3)$ & & $6(1,6)$ \\
\hline VPI2 & $3(1)$ & 0 & & $3(0,8)$ \\
\hline VPI3 & $9(3,1)$ & $4(5,1)$ & & $13(3,5)$ \\
\hline VPI4 & $1(0,3)$ & 0 & & $1(0,3)$ \\
\hline MPVh & $4(1,4)$ & $1(1,3)$ & 1 & $5(1,4)$ \\
\hline $\mathrm{CoV}^{\mathrm{d}}$ & $6(2,1)$ & $2(2,6)$ & 0,65 & $8(2,2)$ \\
\hline Total & 374 & 93 & & 467 \\
\hline \multicolumn{5}{|c|}{$\begin{array}{l}\text { VRS : virus respiratoire syncitial ; AdV : adénovirus ; RhV : rhinovirus ; EntV : entérovirus ; VIA : virus influenza A ; VIB : virus } \\
\text { influenza B ; VIC : virus influenza C ; VPI1 : virus para-influenza } 1 ; \mathrm{VPI} 2 \text { : virus para-influenza } 2 \text {; VPI3 : virus para-influenza } 3 \text {; } \\
\text { VPI4 : virus para-influenza } 4 \text {; MPVh : métapneumovirus humain ; CoV : coronavirus } \\
\text { Les pourcentages correspondent au taux de détection de chaque virus par rapport au nombre d'enfants atteints respectivement de bron- } \\
\text { chiolite }\left({ }^{\mathrm{a}}\right) \text {, pneumonie }\left({ }^{\mathrm{b}}\right) \text { et le total des enfants explorés }\left({ }^{\mathrm{c}}\right) / \text { The percentages correspond to the detection rate of each virus compa- } \\
\text { red to the number of children respectively with bronchiolitis }\left({ }^{a}\right) \text {, pneumonia }(b) \text { and the total number of children explored }\left({ }^{\mathcal{C}}\right) \\
{ }^{\mathrm{d}} \text { Les } 8 \mathrm{CoV} \text { détectés étaient répartis en CoV-NL63 }(n=5), 229 \mathrm{E}(n=2) \text { et HKU1 (un seul cas) / The eight CoVs detected were divi- } \\
\text { ded into CoV-NL63 }(N=5), 229 \mathrm{E}(N=2) \text { and HKU1 }(N=1)\end{array}$} \\
\hline
\end{tabular}

Tableau 2 Prévalence des virus détectés selon le type d'atteinte respiratoire et l'âge des patients / Prevalence of virus detection according to the type of respiratory infection and the age of patients

\begin{tabular}{|c|c|c|c|c|c|c|c|c|c|}
\hline & \multicolumn{3}{|c|}{ Bronchiolite $(n=290)$} & \multicolumn{3}{|c|}{ Pneumonie $(n=78)$} & \multicolumn{3}{|c|}{ Total $(n=368)$} \\
\hline & \multicolumn{2}{|c|}{ Tranches d'âge } & \multirow[t]{2}{*}{$p$} & \multicolumn{2}{|c|}{ Tranches d'âge } & \multirow[t]{2}{*}{$p$} & \multicolumn{2}{|c|}{ Tranches d'âge } & \multirow[t]{2}{*}{$p$} \\
\hline & $\begin{array}{l}1-6 \text { mois } \\
(n=212)\end{array}$ & $\begin{array}{l}>6 \text { mois } \\
(n=78)\end{array}$ & & $\begin{array}{l}1-6 \text { mois } \\
(n=24)\end{array}$ & $\begin{array}{l}>6 \text { mois } \\
(n=54)\end{array}$ & & $\begin{array}{l}1-6 \text { mois } \\
(n=236)\end{array}$ & $\begin{array}{l}>6 \text { mois } \\
(n=132)\end{array}$ & \\
\hline VRS & 114 & 21 & $<10^{-3}$ & 13 & 9 & 0,001 & 127 & 30 & $<10^{-3}$ \\
\hline $\mathrm{AdV}$ & 43 & 34 & $<10^{-3}$ & 7 & 21 & 0,4 & 50 & 55 & $<10^{-3}$ \\
\hline $\mathrm{RhV}$ & 62 & 33 & 0,036 & 8 & 18 & 1 & 70 & 51 & 0,079 \\
\hline EntV & 17 & 7 & 0,79 & 0 & 3 & 0,54 & 17 & 10 & 0,89 \\
\hline VI & 12 & 3 & 0,76 & 3 & 3 & 0,36 & 15 & 6 & 0,47 \\
\hline VPI & 10 & 8 & 0,1 & 1 & 4 & 1 & 11 & 12 & 0,092 \\
\hline MPVh & 0 & 4 & 0,005 & 0 & 1 & 1 & 0 & 5 & 0,006 \\
\hline $\mathrm{CoV}$ & 5 & 1 & 1 & 1 & 1 & 0,52 & 6 & 2 & 0,71 \\
\hline Total & 263 & 111 & & 33 & 60 & & 296 & 171 & \\
\hline
\end{tabular}

AdV qui ont été détectés dans 37 cas et représentant ainsi $71 \%$ des virus retrouvés au cours de cette période. Par ailleurs, les RhV et $\mathrm{AdV}$ ont circulé sans interruption pendant les autres mois alors que les autres virus ont circulé essen- tiellement durant les mois froids de l'année. Parmi les VPI, le sérotype 3, dominant durant l'hiver 2009, a été pratiquement remplacé par le sérotype 1 durant l'hiver suivant. Quant aux CoV et MPVh, ils ont été retrouvés plutôt durant 


\begin{tabular}{|c|c|c|c|c|c|c|c|c|c|}
\hline \multirow{2}{*}{$\begin{array}{l}\text { Virus } \\
\text { détecté }\end{array}$} & \multicolumn{3}{|c|}{ Pneumonie $(n=62)$} & \multicolumn{3}{|c|}{ Bronchiolite $(n=257)$} & \multicolumn{3}{|c|}{ Total $(n=319)$} \\
\hline & $\begin{array}{l}1 \text { virus } \\
n(\%)\end{array}$ & $\begin{array}{l}2 \text { ou } 3 \text { virus } \\
n(\%)\end{array}$ & $p$ & $\begin{array}{l}1 \text { virus } \\
n(\%)\end{array}$ & $\begin{array}{l}2 \text { ou } 3 \text { virus } \\
n(\%)\end{array}$ & $p$ & $\begin{array}{l}1 \text { virus } \\
n(\%)\end{array}$ & $\begin{array}{l}2 \text { ou } 3 \text { virus } \\
n(\%)\end{array}$ & $p$ \\
\hline VRS & $14(41,2)$ & $8(28,6)$ & 0,3 & $77(48,4)$ & $58(59,2)$ & 0,094 & $91(47,2)$ & $66(52,4)$ & 0,36 \\
\hline $\mathrm{AdV}$ & $6(17,6)$ & $22(78,6)$ & $<10^{-3}$ & $10(6,3)$ & $67(68,4)$ & $<10^{-3}$ & $16(8,3)$ & $89(70,6)$ & $<10^{-3}$ \\
\hline $\mathrm{RhV}$ & $10(29,4)$ & $16(57,1)$ & 0,028 & $42(26,4)$ & $53(54,1)$ & $<10^{-3}$ & $52(26,9)$ & $69(54,8)$ & $<10^{-3}$ \\
\hline EntV & $1(2,9)$ & $2(7,1)$ & 0,58 & $6(3,8)$ & $18(18,4)$ & $<10^{-3}$ & $7(3,6)$ & $20(15,9)$ & $<10^{-3}$ \\
\hline VI & $1(2,9)$ & $5(17,9)$ & 0,082 & $11(6,9)$ & $4(4,1)$ & 0,34 & $12(6,2)$ & $9(7,1)$ & 0,74 \\
\hline VPI & $1(2,9)$ & $4(14,3)$ & 0,16 & $8(5)$ & $10(10,2)$ & 0,1 & $9(4,7)$ & $14(11,1)$ & 0,03 \\
\hline $\mathrm{CoV}$ & 0 & $2(7,1)$ & I & $2(1,3)$ & $4(4,1)$ & / & $2(1)$ & $6(4,8)$ & I \\
\hline MPVh & $1(2,9)$ & 0 & I & $3(1,9)$ & $1(1)$ & l & $4(2,8)$ & $1(0,8)$ & l \\
\hline Total & 34 & 28 & & 159 & 98 & & 193 & 126 & \\
\hline
\end{tabular}

Tableau 4 Profil des co-infections à deux et à trois pathogènes (virus ou bactéries atypiques) / Viral and atypical bacteria pathogen coinfection spectra

\begin{tabular}{|c|c|c|c|c|c|}
\hline \multicolumn{3}{|c|}{ Co-infection à deux pathogènes $(n=106)$} & \multicolumn{3}{|c|}{ Co-infection à trois pathogènes $(n=24)$} \\
\hline Pathogène 1 & Pathogène 2 & Nombre & Pathogène $1+2$ & Pathogène 3 & Nombre \\
\hline \multirow[t]{10}{*}{ AdV } & $\mathrm{RhV}$ & 29 & $\mathrm{AdV}+\mathrm{RhV}$ & VRS & 7 \\
\hline & VRS & 29 & & EntV & 1 \\
\hline & EntV & 3 & & CoV-229E & 1 \\
\hline & VIA & 2 & & VPI1 & 1 \\
\hline & VIB & 1 & & VPI3 & 2 \\
\hline & VPI1 & 1 & & VIA & 1 \\
\hline & VPI3 & 4 & & Cpn & 1 \\
\hline & VPI4 & 1 & $\mathrm{AdV}+\mathrm{VRS}$ & EntV & 3 \\
\hline & CoV-NL63 & 1 & & VIC & 2 \\
\hline & Mpn & 1 & $\mathrm{AdV}+\mathrm{EntV}$ & Mpn & 1 \\
\hline \multirow[t]{7}{*}{$\mathrm{RhV}$} & VRS & 12 & $\mathrm{VRS}+\mathrm{RhV}$ & EntV & 3 \\
\hline & EntV & 2 & & VIC & 1 \\
\hline & VIA & 2 & & & \\
\hline & VPI1 & 1 & & & \\
\hline & VPI3 & 3 & & & \\
\hline & MPVh & 1 & & & \\
\hline & CoV-NL63 & 3 & & & \\
\hline \multirow[t]{4}{*}{ VRS } & EntV & 7 & & & \\
\hline & VPI3 & 1 & & & \\
\hline & CoV-229E & 1 & & & \\
\hline & Cpn & 1 & & & \\
\hline
\end{tabular}

la saison hivernale 2010. Les VI étaient détectés durant les deux saisons froides.

\section{Discussion}

Dans cette étude, nous avons recherché le profil étiologique viral et celui des bactéries atypiques des IRB de l'enfant.
Nous avons comparé ce profil selon le type d'atteinte respiratoire, l'âge du patient et la saisonnalité. Cette étude a permis de montrer la prévalence élevée des virus dans ces infections $(86,7 \%)$. Le VRS a été le virus le plus fréquemment détecté suivi par les $\mathrm{RhV}$ puis les AdV. La fréquence de détection du VRS était significativement plus élevée dans les bronchiolites que dans les pneumonies, alors que les $\mathrm{AdV}$ étaient plus fréquemment détectés chez les enfants 


\begin{tabular}{|c|c|c|c|c|c|c|c|c|}
\hline & VRS & $\mathbf{R h V}$ & AdV & VI & VPI & EntV & MPVh & $\mathrm{CoV}$ \\
\hline Janvier 2009 & 52 & 7 & 13 & 2 & 4 & 8 & & \\
\hline Février 2009 & 67 & 14 & 16 & 7 & 2 & 9 & & 1 \\
\hline Mars 2009 & 31 & 16 & 24 & 3 & 2 & 5 & & \\
\hline Avril 2009 & 1 & 9 & 13 & 1 & 3 & & & \\
\hline Mai 2009 & 1 & 4 & 5 & & 2 & 2 & & \\
\hline Juin 2009 & 1 & 2 & 1 & & & & & \\
\hline Juillet 2009 & & 5 & 1 & & & & & \\
\hline Août 2009 & & 2 & 3 & & 1 & & & \\
\hline Septembre 2009 & & 4 & 2 & & & & & \\
\hline Octobre 2009 & & 13 & 5 & & 2 & 1 & & \\
\hline Novembre 2009 & 1 & 7 & 3 & & 7 & & & \\
\hline Décembre 2009 & & 13 & 7 & 7 & & 1 & 1 & 1 \\
\hline Janvier 2010 & & 4 & 3 & & & & & \\
\hline Février 2010 & 1 & 13 & 3 & & & & 3 & 2 \\
\hline Mars 2010 & 2 & 8 & 6 & 1 & & 1 & 1 & 4 \\
\hline Total & 157 & 121 & 105 & 21 & 23 & 27 & 5 & 8 \\
\hline
\end{tabular}

atteints de pneumonie. Le VRS est connu comme la principale cause d'IRB chez les enfants âgés de moins de cinq ans $[6,7,10,16,19,21,22]$. Les RhV qui constituent la cause la plus commune des infections respiratoires hautes peuvent aussi se répliquer en même temps dans les voies aériennes inférieures. Ils sont ainsi détectés chez 10 à $34 \%$ des enfants atteints d'IRB et jusqu'à $25 \%$ dans les pneumonies de l'enfant $[2,4,6,7,10,15,16,19,21]$. Cependant, on rapporte également leur détection chez les personnes asymptomatiques avec une fréquence allant en moyenne jusqu'à $15 \%$ [17]. De plus, la détection des RhV par PCR reste positive jusqu'à cinq semaines après une infection aiguë [18]. De même pour les $\mathrm{AdV}$, des études récentes ont montré la détection plus fréquente de ces virus chez les enfants témoins que chez les enfants symptomatiques [3,23]. Ainsi, le rôle pathogène des $\mathrm{AdV}$ et $\mathrm{RhV}$ dans les IRB n'est pas toujours évident, et ce, d'autant que plusieurs auteurs ont rapporté la fréquence de codétection de ces virus avec d'autres pathogènes $[2,4,27]$. Les co-infections virus-virus ou virus-bactérie suscitent aujourd'hui beaucoup d'attention et posent la question quant à leur signification clinique dans les IRB, étant donné leur détection aussi chez des enfants asymptomatiques. Des études récentes, utilisant les outils de biologie moléculaire, retrouvent des co-infections virales à deux virus ou plus chez 4 à $59 \%$ des enfants atteints d'IRB [2,3,7,19,27]. Dans notre étude, les codétections virus-virus ou virus-bactérie ont concerné $40 \%$ des patients. Les associations retrouvées étaient dominées par AdV + RhV, AdV + VRS et RhV + VRS. De plus, les AdV, RhV et VPI (en particulier le sérotype 3) étaient significativement plus fréquemment retrouvés en co-infection que comme seuls pathogènes, contrairement au VRS qui était retrouvé dans 47,2\% des ANP à un seul virus alors qu'il vient en troisième position dans les coinfections. D'autres études ont rapporté également la prédominance du VRS dans les mono-infections [2,4,15,27]. Il a été montré que le pourcentage de co-infections augmente au cours de la saison froide lorsque le nombre de virus respiratoires circulants est plus élevé [7]. En fait, l'identification de deux virus ou plus chez un même patient peut être due à une co-infection réelle, comme elle peut être due à une excrétion virale prolongée ou à la persistance asymptomatique de l'un des virus dans les voies aériennes après la guérison de l'infection antérieure. La quantification du génome viral par PCR en temps réel pourrait être utile pour mieux expliquer ces co-infections. Concernant le rôle des VI dans les IRB, ils sont moins fréquemment retrouvés chez l'enfant que chez l'adulte et le sujet âgé, et leur incidence varie considérablement d'une année à l'autre. Dans notre étude, ces virus ont été détectés chez uniquement $5,7 \%$ des enfants explorés. Plusieurs études, effectuées en dehors de la période de pandémie grippale, ont aussi enregistré des taux de détection faibles allant de 0,8 à $10 \%$ chez les enfants atteints d'IRB $[6,10,16,20,21]$. Quant au reste des virus explorés dans notre étude, leur taux de détection a été faible allant de 1,4\% pour le MPVh à 7,3\% pour les EntV.

La moyenne d'âge de nos patients était de 7,03 mois. Seuls cinq enfants étaient âgés de plus de cinq ans. En effet, les IRB se voient essentiellement chez l'enfant âgé de moins de cinq ans $[2,4,14,16,19,26]$. Par ailleurs, le VRS était plus fréquemment détecté chez les nourrissons âgés de moins de six mois dans notre étude. Ce résultat est concordant avec celui d'autres auteurs $[4,12,27]$. La prédominance de 
l'infection respiratoire à VRS durant la première année de vie peut être expliquée par le fait que les anticorps maternels transmis au nourrisson interfèrent avec le développement des premières réponses humorales après la primo-infection à VRS. Ainsi, la production d'anticorps neutralisants est très diminuée par rapport à celle observée chez les enfants plus âgés chez lesquels les réinfections sont fréquentes mais souvent cliniquement muettes, jouant ainsi un rôle important dans la diffusion de la maladie [5]. Chez les enfants âgés de plus de six mois, c'est l'AdV qui était le plus détecté dans notre étude, à l'instar d'autres études [2,4,12,27].

Quant aux bactéries atypiques, Mpn a été détectée chez deux enfants $(0,5 \%)$ et $\mathrm{Cpn}$ chez trois autres $(0,8 \%)$. Ce faible taux peut être expliqué par le recrutement hospitalier des patients inclus, alors que ces germes sont en général responsables de pneumopathies bénignes ne nécessitant pas l'hospitalisation et sont traités plutôt en ambulatoire. D'une part, ces bactéries se voient plus chez les enfants d'âge scolaire $[14,26]$ alors que la majorité de nos patients étaient âgés de moins de cinq ans. D'autre part, ces agents pathogènes ont été détectés associés à un ou deux virus chez quatre de nos patients ce qui laisse poser la question sur leur rôle étiologique réel. Spuesens et al. n'ont pas trouvé de différence significative dans la fréquence de détection de Mpn entre les enfants symptomatiques et asymptomatiques, et ce, quelle que soit la technique utilisée [25].

Les infections respiratoires virales ont un caractère épidémique et saisonnier dans le monde entier, survenant essentiellement pendant la saison froide. Dans les pays tempérés, elles sont très fréquentes en saison hivernale, de novembre à février, période de diffusion majeure des deux principaux virus épidémiques, le VRS chez l'enfant et les VIA et VIB chez l'adulte. Elles peuvent aussi être observées en septembre-octobre et en mars-avril sous forme de petites épidémies [9]. Dans notre étude, la majorité des ANP ont été reçues au laboratoire durant les deux saisons froides correspondant aux mois de janvier à mars en 2009 et en 2010. La majorité, soit $71 \%$ du total des virus, a été également détectée durant ces deux saisons. La principale étiologie retrouvée durant l'hiver 2009 était le VRS. Bien que le VRS présente un profil saisonnier généralement stéréotypé et une cinétique conservée d'une année à l'autre [9,12], la prédominance en 2009 de ce virus dans notre étude n'a pas été retrouvée les mêmes mois de l'année suivante puisqu'il a été quasiment remplacé par RhV et AdV. En fait, l'hiver 2009-2010 a coïncidé avec la pandémie H1N1 où le VIA a prédominé, contrairement au VRS qui a presque disparu. Le faible taux de détection des VI dans notre étude peut être expliqué par le fait que, durant la pandémie H1N1, les enfants suspects d'avoir une infection respiratoire virale ont été hospitalisés, non pas dans le service de pédiatrie, mais dans l'unité H1N1 qui a été créée dans le service de pneumologie par les autorités sanitaires tunisiennes dans le cadre de la riposte contre le virus
H1N1. Ces enfants n'ont donc pas été inclus. Quant aux $\mathrm{RhV}$ et $\mathrm{AdV}$, ils ont circulé tout au long de la période d'étude avec un pic à la fin de l'hiver et une recrudescence à partir d'octobre. Ces deux virus sont connus endémiques et circulent classiquement tout au long de l'année [2,12,15], avec une nette augmentation des infections à $\mathrm{RhV}$ au printemps et en automne, période où les deux principaux virus respiratoires, le VRS et les VI, circulent peu ou pas $[9,11,12]$.

\section{Conclusion}

Dans notre étude, le VRS représente la première étiologie virale des IRB de l'enfant, en particulier des bronchiolites. Il est plus fréquent chez le nourrisson âgé de moins de six mois et dans les IRB à un seul virus. Les RhV et AdV occupent également une place importante dans les étiologies virales de cette pathologie, souvent codétectés avec d'autres virus. Avec l'introduction des techniques moléculaires pour la recherche des virus respiratoires et des bactéries atypiques, la fréquence de codétection de plusieurs pathogènes dans un même prélèvement a augmenté sans que leur signification clinique soit clairement explicite.

Remerciements Nos vifs remerciements sont adressés à toutes les personnes du laboratoire de microbiologie, du service de pédiatrie des CHU de Sfax ou du laboratoire de virologie du CHU de Caen qui ont participé à ce travail. Nous remercions en particulier nos trois techniciennes de laboratoire, Mmes Noura Abdelmoula, Najoua Yaïch et Chefia Cherni pour leur contribution technique

Liens d'intérêt : les auteurs déclarent ne pas avoir de liens d'intérêt.

\section{Références}

1. Bellau-Pujol S, Vabret A, Legrand L, et al (2005) Development of three multiplex RT-PCR assays for the detection of 12 respiratory RNA viruses. J Virol Methods 126:53-63

2. Bezerra PG, Britto MC, Correia JB, et al (2011) Viral and atypical bacterial detection in acute respiratory infection in children under five years. PLoS One 6:e18928. doi: 10.1371/journal. pone. 0018928

3. Bhuyan GS, Hossain MA, Sarker SK, et al (2017) Bacterial and viral pathogen spectra of acute respiratory infections in under-5 children in hospital settings in Dhaka city. PLoS One 12: e0174488. doi: 10.1371/journal.pone.0174488

4. Bicer S, Giray T, Çöl D, et al (2013) Virological and clinical characterizations of respiratory infections in hospitalized children. Ital J Pediatr 39:22. doi: 10.1186/1824-7288-39-22

5. Brandenburg AH, Groen J, van Steensel-Moll HA, et al (1997) Respiratory syncytial virus specific serum antibodies in infants under six months of age: limited serological response upon infection. J Med Virol 52:97-104 
6. Chen YW, Huang YC, Ho TH, et al (2014) Viral etiology of bronchiolitis among pediatric inpatients in Northern Taiwan with emphasis on newly identified respiratory viruses. J Microbiol Immunol Infect 47:116-21. doi: 10.1016/j.jmii.2012.08.012

7. Cilla G, Oñate E, Perez-Yarza EG, et al (2008) Viruses in community-acquired pneumonia in children aged less than 3 years old: high rate of viral coinfection. J Med Virol 80:1843-9. doi: 10.1002/jmv. 21271

8. Dina J, Nguyen E, Gouarin S, et al (2009) Development of duplex real-time PCR for detection of two DNA respiratory viruses. J Virol Methods 162:119-25. doi: 10.1016/j.jviromet.2009.07.025

9. Freymuth F, Vabret A (2008) Les viroses respiratoires aiguës en pratique : le point de vue du virologue. XIII ${ }^{\mathrm{e}}$ Journée nationale des GROG - Paris, le 13 novembre 2008, 2 p

10. Freymuth F, Vabret A, Cuvillon-Nimal D, et al (2006) Comparison of multiplex PCR assays and conventional techniques for the diagnostic of respiratory virus infections in children admitted to hospital with an acute respiratory illness. J Med Virol 78:1498-504

11. Freymuth F, Vabret A, Dina J, et al (2007) Techniques actuelles de diagnostic des infections virales respiratoires en réanimation. Réanimation 16:200-9

12. Freymuth F, Vabret A, Dina J, et al (2010) Les virus des bronchiolites aiguës. Arch Pediatr 17:1192-201

13. Hardegger D, Nadal D, Bossart W, et al (2000) Rapid detection of Mycoplasma pneumoniae in clinical samples by real-time PCR. J Microbiol Methods 41:45-51

14. Heath PT (2000) Epidemiology and bacteriology of bacterial pneumonias. Paediatr Respir Rev 1:4-7

15. Hoffmann J, Rabezanahary H, Randriamarotia M, et al (2012) Viral and atypical bacterial etiology of acute respiratory infections in children under 5 years old living in a rural tropical area of Madagascar. PLoS One 7:e43666. doi: 10.1371/journal.pone.0043666

16. Huang G, Yu D, Mao N, et al (2013) Viral etiology of acute respiratory infection in Gansu Province, China, 2011. PLoS One 8: e64254. doi: 10.1371/journal.pone.0064254

17. Jartti T, Jartti L, Peltola V, et al (2008) Identification of respiratory viruses in asymptomatic subjects: asymptomatic respiratory viral infections. Pediatr Infect Dis J 27:1103-7. doi: 10.1097/INF.0b013e31817e695d

18. Jartti T, Lehtinen P, Vuorinen T, et al (2004) Persistence of rhinovirus and enterovirus RNA after acute respiratory illness in children. J Med Virol 72:695-9
19. Juvén T, Mertsola J, Waris M, et al (2000) Etiology of community-acquired pneumonia in 254 hospitalized children. Pediatr Infect Dis J 19:293-8

20. Kwofie TB, Anane YA, Nkrumah B, et al (2012) Respiratory viruses in children hospitalized for acute lower respiratory tract infection in Ghana. Virol J 9:78. doi: 10.1186/1743-422X-9-78

21. Michelow IC, Olsen K, Lozano J, et al (2004) Epidemiology and clinical characteristics of community-acquired pneumonia in hospitalized children. Pediatrics 113:701-7

22. Nair H, Nokes DJ, Gessner BD, et al (2010) Global burden of acute lower respiratory infections due to respiratory syncytial virus in young children: a systematic review and meta-analysis. Lancet 375:1545-55. doi: 10.1016/S0140-6736(10)60206-1

23. Rhedin S, Lindstrand A, Hjelmgren A, et al (2015) Respiratory viruses associated with community-acquired pneumonia in children: matched case-control study. Thorax 70:847-53. doi: 10.1136/thoraxjnl-2015-206933

24. Rudan I, O'Brien KL, Nair H, et al (2013) Epidemiology and etiology of childhood pneumonia in 2010: estimates of incidence, severe morbidity, mortality, underlying risk factors and causative pathogens for 192 countries. J Glob Health 3:1-14. doi: 10.7189/jogh.03.010401

25. Spuesens EB, Fraaij PL, Visser EG, et al (2013) Carriage of Mycoplasma pneumoniae in the upper respiratory tract of symptomatic and asymptomatic children: an observational study. PLoS Med 10:e1001444. doi: 10.1371/journal.pmed.1001444

26. Stein RT, Marostica PJC (2006) Community-acquired pneumonia. Paediatr Respir Rev 7:136-7

27. Sung RY, Chan PK, Tsen T, et al (2009) Identification of viral and atypical bacterial pathogens in children hospitalized with acute respiratory infections in Hong Kong by multiplex PCR assays. J Med Virol 81:153-9. doi: 10.1002/jmv.21364

28. Vabret A, Dina J, Gouarin S, et al (2006) Detection of the new human coronavirus HKU1: a report of 6 cases. Clin Infect Dis 42:634-9

29. Vabret A, Mourez T, Dina J, et al (2006) Human coronavirus NL63, France. Emerg Infect Dis 11:1225-9

30. Welti M, Jaton K, Altwegg M, et al (2003) Development of a multiplex real-time quantitative PCR assay to detect Chlamydia pneumoniae, Legionella pneumophila and Mycoplasma pneumoniae in respiratory tract secretions. Diagn Microbiol Infect Dis $45: 85-95$ 